\title{
Literacia científica: leitura e produção de textos científicos
}

\section{Scientific literacy: reading and writing of scientific texts}

\author{
José Morais ${ }^{1}$ \\ Régine Kolinsky²
}

\begin{abstract}
RESUMO
Após discussão do termo e do conceito de literacia, da sua história e do seu contexto sociocultural, são referidas as condições da aprendizagem da leitura e da escrita no sistema alfabético e distinguidos diferentes tipos de "letrado". É apresentado o subconceito de literacia científica, esboçada a sua história e discutida a sua ambiguidade, concluindo que ele deve incluir tanto a produção escrita da ciência como o conhecimento e compreensão que as pessoas têm desta. É analisada e comentada a parte de leitura e de produção de texto na atividade científica, assim como a relação íntima entre leitura e escrita de texto, e são considerados os hábitos e as exigências das publicações. São ilustrados os baixos níveis da "consciência científica" na população, inclusive na estudantil, e do ensino da ciência na escola, é recomendada a leitura precoce de artigos científicos e considerada favoravelmente a tendência atual à aproximação e em certos casos integração das literacias científica e literária. O estado da literacia (mais precisamente da capacidade de leitura) no contexto da globalização capitalista neoliberal e no Brasil em particular são considerados como travões à generalização da literacia científica. Enfim, é defendida a importância da ciência experimental da cognição e da linguagem e de uma maior orientação do ensino para o desenvolvimento das capacidades de "inteligência fluida".
\end{abstract}

Palavras-chave: literacia; literacia científica; literacia literária; ciência da literacia; ensino da ciência.

DOI: $10.1590 / 0104-4060.48025$

1 Université Libre de Bruxelles. Unité de Recherche en Neurosciences Cognitives Center for Research in Cognition \& Neurosciences. Bruxelles, Belgium. Av. F. D. Roosevelt, 50 B -1050. E-mail: jmorais@ulb.ac.be

2 Université Libre de Bruxelles. Unité de Recherche en Neurosciences Cognitives, CP 191. Bruxelles, Belgium. Av. F. D. Roosevelt, 50 B - 1050.E-mail: rkolins@ulb.ac.be 


\begin{abstract}
Following a discussion of the literacy word and concept, of its history and sociocultural context, we refer the conditions of learning how to read and write in the alphabetic system and we distinguish kinds of "literates". We examine the sub-concept of scientific literacy, considering its history and discussing its ambiguity, concluding that it ought to include both the written production of science and the knowledge and understanding people have of it. We analyze and comment the textual reading and writing components of scientific activity, as well as their intimate relationship, and we consider some aspects of the publications' rules and demands. We illustrate the low levels of the "scientific awareness" of the population, even among students, and of science teaching in schools, recommending the early reading of scientific papers, and considering as positive the trend for an approximation, in some cases integration, of scientific and literary literacies. We argue that the state of literacy (more precisely of reading capacity) in the global neoliberal capitalist society, in particular in Brazil, counters the generalization of scientific literacy. Finally, we propose to support the development of experimental research on cognition and language, and to look for how school teaching can better foster "fluid intelligence" capacities.
\end{abstract}

Keywords: literacy; scientific literacy; literary literacy; literacy science; science teaching.

Tendo nós decidido referir o objeto deste artigo, destinado prioritariamente aos leitores brasileiros, pela expressão "literacia científica", impõe-se começá-lo por justificar a escolha do substantivo "literacia".

\title{
Literacia: as razões deste conceito e o que ele recobre
}

"Literacia", palavra hoje utilizada abundantemente em Portugal para referir de modo geral o fato de saber ler e escrever, provém do inglês literacy, criado no último quarto do $19^{\circ}$ século a partir do francês e do latim para designar o alfabetismo e por oposição a illiteracy, analfabetismo. Literacy expandiu-se por todo o mundo, devido ao poder colonizador da língua inglesa. Entre as regiões de língua francesa, a província do Québec foi a primeira a adotar "littératie". O termo (com esta grafia) já foi adotado pela Organização para a Cooperação e Desenvolvimento Econômico (OCDE). Foi também adotado pelos países francófonos da Europa, em alguns com grafias um pouco diferentes - um " $t$ ” em vez 
de dois, ou a terminação "-cie". Com a exceção da França, onde os linguistas e psicolinguistas o utilizam correntemente, mas onde as instituições oficiais e acadêmicas resistem tanto quanto podem. (cf. MORAIS, 2016).

No seio da mesma língua, é a portuguesa que exibe, entre os dois países com maior influência cultural, um contraste flagrante. Enquanto em Portugal, literacia é utilizado pelas instituições oficiais, nas Universidades e escolas, e nos meios de comunicação, no Brasil este termo é praticamente inexistente, devido à re-emergência, nos anos 1980, do termo "letramento", há muito caído em desuso, agora com uma intenção sociopolítica de prática libertadora. Porém, como a História é impiedosa, mesmo as boas intenções são esmagadas e, hoje em dia, já se fala muito de, por exemplo, "letramento financeiro" das crianças num contexto de adaptação, pela educação financeira, à sociedade capitalista neoliberal. Note-se que, tanto em Portugal como no Brasil, literacia e educação se referem a dois conceitos distintos: educação é mais geral e, sobretudo, é a via pela qual se obtém a literacia ou o letramento, podendo estas se declinar em função do domínio (informacional, financeiro, sanitário, etc.).

Apresentado o contexto terminológico, podemos indicar por que razões utilizamos literacia. Elas são três.

Primeira razão: Enquanto literacy, de onde provém literacia, não nasceu com uma intenção ideológica, letramento tem uma carga ideológica e afetiva que, por mais meritória que seja, não é condicente com a objetividade de um exame intencionalmente científico e rigoroso (portanto neutro, tanto quanto é possível ser-se neutro).

A segunda razão relaciona-se com o significado da componente final das duas expressões. Letrado é muito mais frequente que literato (o qual provém diretamente do latim), e é, portanto, aquele que utilizamos para designar o indivíduo que dispõe de literacia (mais adiante distinguiremos entre alfabetizado e letrado). Porém, o significado dos constituintes finais é diferente. Enquanto o sufixo -mento faz com que seja referido o ato ou efeito de letrar (palavra inexistente em português, mas isso não constituiria um óbice, além de que existe "letrar-se"), a terminação -cia evoca de preferência a "arte" (no sentido de habilidade, capacidade) e o conjunto dos processos nela envolvidos. Isso é justamente aquilo para que nós, psicolinguistas, devemos chamar a atenção. Não se compreende a leitura e a escrita, e não se propõem as melhores maneiras de ensinar a ler e escrever, enquanto não se conhecerem os processos que "fazem" estas artes de ler e escrever. Como é sabido, embora não de todos, estes processos são já conhecidos em grande medida, mas - como acontece em todas as ciências - falta, na nossa, conhecer ainda muito mais finamente a dinâmica temporal desses processos, as conexões neurais envolvidas, a influência das características da língua e do código ortográfico, as razões precisas das dificul- 
dades encontradas, etc. Literacia é, portanto, mais conveniente para designar os processos ("a arte") da leitura e da escrita.

A última razão é pragmática. Nós temos de nos entender, todos, e não apenas no interior de um país ou só entre falantes do Português. É mais fácil entendermo-nos quando lemos ou ouvimos literacy, littératie, literacia, do que quando usamos letramento.

Adotamos, portanto, o termo "literacia". No entanto, esse termo, assim como a expressão "aprender a ler e a escrever" é subdeterminado, tal como o é "aprender a jogar", já que podemos aprender a jogar futebol, tênis, xadrez, cartas, etc. De fato, podemos aprender a ler e escrever uma escrita alfabética, ou um abjad (escrita em que o mesmo símbolo designa todas as sílabas que partilham a mesma consoante), ou uma escrita morfossilábica, ou uma escrita ideográfica, etc. É o nosso alfabeto-centrismo que nos faz esquecer que não somos únicos neste mundo. Mas não há mal em que assim seja se a opção for definida uma vez por todas. Neste texto, falamos, portanto, de literacia alfabética (a nossa), sem necessidade de repetir a expressão a cada vez.

Omitiremos também este adjetivo quando falarmos de letrado. Assim, no quadro da escrita alfabética, distinguimos entre o alfabetizado e o letrado e consideramos vários tipos de letrado. (MORAIS, 2016). O alfabetizado é aquele que pode ler uma escrita alfabética, incluindo palavras escritas que nunca tinha encontrado, e escrever a fala de outrem e eventualmente a sua própria fala interna. Isso é possível se aprendeu, de algum modo, o código ortográfico dessa língua. Sendo a sua própria língua, pode ler com compreensão e escrever frases com sentido. Porém, como lê e escreve utilizando processos de decodificação e de recodificação que são conscientes, controlados, sequenciais e, portanto, lentos, a focalização da atenção sobre esses processos e a sobrecarga na memória de trabalho influenciam negativamente tanto a compreensão como a qualidade da escrita. Dizemos dele que lê e escreve com autonomia (faz sem precisar mais de um instrutor ou de um tutor), mas ainda não de maneira automática, e atribuímos este último modo de processamento àquele a quem, tendo deixado de ser simplesmente alfabetizado, chamamos "letrado".

O que quer dizer ler e escrever com automaticidade? Quer dizer que, na leitura, a identificação das palavras escritas se faz muito rapidamente, muitas vezes na base de uma única fixação ocular por palavra, outras vezes mais do que uma, mas sem consciência dos processos subjacentes que conduzem à tomada de consciência de como cada palavra se pronuncia e o que significa, e que, na escrita, tendo pensado em uma palavra, encontra a maneira como ela se escreve, também em bloco e sem esforço de procura. São estes processos que a psicologia cognitiva experimental procura pôr em evidência. E é esta ciência que, estudando a fase de aprendizagem, tem mostrado que é a prática com 
sucesso de decodificação e recodificação que conduz ao estabelecimento desta leitura e escrita automáticas. Este processamento rápido e eficiente libera as capacidades cognitivas conscientes, aquelas que podemos controlar pelo menos até certo ponto (atenção, memória, raciocínio), para a compreensão profunda e a produção clara e estruturada de textos.

Podemos distinguir entre três tipos de letrado, em função do que ele faz utilizando suas capacidades de leitura e escrita autônomas. O tipo de letrado mais frequente é o letrado simplesmente produtivo (ou reprodutivo), aquele que utiliza estas capacidades para adquirir conhecimento (pela leitura) e para comunicar informação (pela escrita).

Há letrados, porém, que não são simplesmente (re)produtivos, mas que criam algo de novo a partir das suas leituras e o fazem conhecer através da escrita. Pode ser conhecimento, pode ser, de modo mais geral, informação, pode também ser expressão de emoções, de afetos, de ideias. Entre estes letrados inovadores, inventivos, estão os letrados científicos, eles descobrem conhecimento e transmitem este novo conhecimento.

Finalmente, há o tipo de letrado (bem mais raro), que através das suas capacidades e atividades de literacia consegue formular uma teoria, uma concepção geral no seio de um domínio ou cobrindo mais do que um domínio, que abre caminho para uma nova maneira de interpretar, conceitualizar, exprimir o mundo e nós próprios. Pode, dependendo do domínio e da forma de expressão, ser um letrado científico, um letrado filósofo, um letrado literário, um letrado ideólogo, etc.

O que, em todo o caso, une estes dois tipos de letrado, que diferem pelo impacto da sua criação ("doméstica”, isto é, no seu domínio, ou pelo contrário transversal, integradora, ou profundamente transformadora), é que em ambos a criação pressupõe uma utilização livre e crítica da literacia. A liberdade de pensamento e de expressão e o pensamento crítico são as duas condições que toda sociedade, todo governo, todo sistema educativo, deve garantir e estimular. Sem liberdade e sem espírito crítico não há renovação nem aprofundamento da literacia. E quando liberdade e espírito crítico são ameaçados, para defendê-los é necessário que os letrados e a literacia se mantenham firmes, inalteráveis e irreverentes, custe o que custar, face à opressão e à repressão.

\section{A literacia científica: História desta noção}

A noção de literacia científica nasceu no fim dos anos 1950 para designar não a produção científica escrita - que deveria estar incluída -, mas apenas o 
conhecimento que as pessoas têm da ciência. Por analogia, seria como se a literacia literária não incluísse a produção literária - a literatura -, nem a crítica literária, mas apenas em que medida as pessoas leem ou, mais superficialmente, conhecem obras literárias. Neste texto defendemos a posição que consiste em considerar ambas as componentes, já que o conhecimento que se tem de um setor de literacia depende das características e do contexto da sua produção.

No caso da literacia científica, pode explicar tal limitação o fato de esta noção se ter desenvolvido num contexto de discussões essencialmente ideológicas e políticas. Como explica De Boer (2000), o lançamento do primeiro Sputnik em 1957 terá influenciado imediatamente, entre outros escritos, o relatório do "Board" do "Rockfeller Brothers Fund" sobre educação, publicado em 1958. Este falava da necessidade de desenvolver o conhecimento em áreas como a energia nuclear, a exploração espacial, a biologia celular, a fisiologia cerebral. Nos anos seguintes, os relatórios das associações de professores, nomeadamente da "National Science Teachers Association" (NSTA), foram no mesmo sentido e insistiram no conhecimento dos conteúdos. Porém, no início dos anos 1970, surgiu uma outra perspectiva. A mesma associação de professores anunciou que o indivíduo cientificamente letrado é aquele que " [...] compreende as inter-relações entre ciência, tecnologia e outras facetas da sociedade, incluindo o desenvolvimento social e econômico". (NSTA, 1971, p. 47-48; a tradução desta e das outras frases citadas abaixo é da nossa responsabilidade). Durante mais de uma década, a tendência dominante, designada por STS (Science-Technology-Society), foi considerar a ciência no seu contexto social. Uma implicação desta perspectiva foi a ideia de que os temas não deviam ser organizados em função de conteúdos disciplinares mas sim de "questões sociais". Obviamente, isto suscitou críticas, baseadas no contra-argumento de que as questões sociais "[...] não transmitem nenhuma compreensão real do que é a integridade estrutural da ciência" e de que, além disso, "os fundamentos, simplesmente, não são ensinados". (KROMHOUT; GOOD, 1983, p. 649).

Esta discussão prolongou-se nos anos 1990 e os "National Science Education Standards" de 1996 privilegiaram a compreensão da ciência e do processo científico. Refletindo esta orientação, escreveu-se o seguinte:

A literacia científica significa que se é capaz de ler com compreensão artigos sobre a ciência na imprensa popular e encetar conversas sobre a validade das suas conclusões. Um cidadão letrado deve ser capaz de avaliar a qualidade da informação científica a partir da sua fonte e dos métodos utilizados para gerá-la. (COLLINS, 1998, p. 22). 
Há, no entanto, alguma ambiguidade nesta definição. Na primeira frase, diz-se que a literacia científica inclui compreender textos sobre ciência, mas não que ela inclui a compreensão de textos de ciência. Porém, a segunda frase vai mais longe: será que "ter em conta a fonte e os métodos" implica que se deve ler a informação científica na fonte? De qualquer modo, esta definição não se refere aos que leem, fazem e escrevem ciência. Também houve quem pensasse que são fúteis os esforços para desenvolver a literacia científica através da educação. Para Shamos (1995), era ingênuo pensar que os alunos pudessem aprender a pensar como os cientistas. Além disso, as questões sociais que os pudessem interessar pouco tinham a ver com a ciência. Shamos pensava que mais valia falar-lhes de tecnologia por ser mais útil e menos abstrata. Para ele, literacia científica significava, sobretudo, ter uma ideia (awareness) de como a tecnologia e a ciência funcionam. As decisões que envolvem informação científica seriam para os especialistas. O que, entre outras coisas, ele subestimava, embora seja um fato que na época não era tão visível, é a tendência para que cada vez mais jovens se tornem cientistas.

Assim, até ao começo deste século, literacia científica significava essencialmente a compreensão que o público tem da ciência. Não abrangia a produção escrita dos cientistas. De Boer (2000) exprimiu isso mesmo e até deu a entender que a separação entre a sociedade e a ciência, para além de inevitável, não seria problemática: “[...] as pessoas com uma compreensão extremamente limitada da ciência funcionam muito bem na sociedade, muitas estão nos níveis de topo das suas profissões. Além disso, o ritmo de ocorrência de descobertas científicas e tecnológicas não diminui". (DE BOER, 2000, p. 594). Afinal, tudo ia bem no melhor dos mundos.

\section{A literacia científica, constitutiva da ciência}

Já neste século, ganhou importância a ideia de que, na expressão "literacia científica", é necessário dar mais relevo à componente "literacia", no sentido de capacidade e atividade de leitura e escrita ("to focus on the literacy aspects of scientific literacy", Webb (2010), na mais prestigiosa revista científica norte-americana, Science), isto é, àquilo que Norris e Phillips (2003) chamaram o "sentido fundamental" da literacia científica: "[...] a leitura e a escrita não têm apenas uma relação funcional com a ciência, como simples instrumentos para conservar e transmitir ciência. Na realidade, [...] a leitura e a escrita são partes constitutivas da ciência." (NORRIS; PHILLIPS, 2003, p. 226). Ser proficiente 
em ciência não é só ser capaz de raciocinar, imaginar, planificar, deliberar, argumentar, é também ser capaz de falar, ler e escrever ciência.

Estes autores calcularam que os cientistas passam quase dois terços do seu tempo de aquisição de informação em atividades de leitura, e quase um quarto $(23 \%)$ do seu tempo total de trabalho por dia. (TENOPIR; KING, 2004; cf. também NORRIS et al., 2008). Ler, escrever e falar, tudo o que é comunicação, representam 58\% do tempo que os pesquisadores dedicam à ciência. Eles próprios consideram que ler é a sua principal fonte de estimulação criadora.

Todos os que trabalham com ciência sabem que tiveram de adquirir estratégias de procura e de interpretação da informação, tanto para localizar os artigos pertinentes como durante a leitura; que muitas vezes não se vai além do resumo; que é raríssimo ler um artigo de maneira linear do princípio ao fim, mas que alguns são revisitados regularmente. Há uma constância na estrutura informacional e gráfica dos artigos que permite identificar rapidamente o que é importante. É fácil ir diretamente ao estado da arte, às hipóteses, ao plano experimental, aos dados, às inferências, às conclusões. Há uma expectativa de certos padrões de argumentação, de conexões entre afirmações, suposições, justificações, evidências. E todos conhecem as graduações sutis de incerteza nos condicionais e outras expressões.

No que respeita à fase de produção do texto científico, as estratégias são diversas e podem depender do domínio, do tipo de texto (teórico, experimental, resenha). A estrutura clássica do texto de uma contribuição inovadora e relatora de trabalho experimental é a sequência Resumo, Introdução, Método, Resultados, Discussão e Bibliografia. Porém, há revistas (incluindo algumas importantes) em que o método é apresentado depois dos resultados, e outras em que é anexado ao artigo um documento contendo material suplementar, em geral detalhes metodológicos e/ou análises adicionais. A estrutura do texto publicado não é necessariamente seguida durante a sua produção. Muitos autores começam por escrever o Método e os Resultados, o que tem sentido na medida em que são partes factuais em que são raras as frases de comentário ou de interpretação. No entanto, é obvio que os autores sabem o que fizeram e conhecem os resultados antes de se lançarem à escrita, por isso, nesta, muitos, talvez a maioria, começam por "assentar" as ideias redigindo uma Introdução que pode vir a ser largamente corrigida, e assim a sucessão mais frequente é a do produto acabado com exceção do Resumo, geralmente o último a ser escrito. De qualquer modo, devido à função particular de cada uma das suas partes, a produção de texto científico é altamente específica relativamente aos outros tipos de texto. Não se imagina algo semelhante na escrita (embora possa acontecer na elaboração mental) de um libreto de ópera ou de um romance.

A literacia científica distingue-se das outras formas de literacia por uma interpenetração quase total da atividade de leitura e de escrita. Para além do fato 
óbvio de que, qualquer que seja o gênero de texto, em geral vamos lendo o que escrevemos e que, por vezes, podemos tomar nota de alguma ideia enquanto lemos, na ciência não há leitor que não seja escritor, nem escritor que não seja leitor. Cada cientista lê os artigos dos outros, mas também os dos seus coautores, e os seus próprios, revistos pelos coautores. Regularmente, tem de escrutinar artigos submetidos para publicação, para escrever sobre eles, muitas vezes várias páginas, analisá-los ao nível das ideias e dos detalhes, avaliá-los, criticá-los, depois de procurar informações pertinentes na memória ou na literatura, para finalmente propor a sua publicação, revisão ou rejeição. Certos artigos podem assim morrer às suas mãos, às dos outros revisores e às do editor. Nós mesmos já tivemos alguns que morreram assim, e também já assassinamos outros. Satisfazer os revisores é toda uma arte: é preciso lê-los bem para escrever melhor. Um de nós (JM) foi coautor de um artigo que tivemos de submeter cinco vezes. Quando foi publicado estava quase irreconhecível, mas muito melhor do que na primeira versão. São obras a muitas mãos. Na literacia científica, não há fronteiras claras entre a leitura e a escrita, e cada artigo publicado é trigo que passou por muitas peneiras. Também não se encontra ilustração mais forte de intertextualidade do que a da literacia científica. De fato, temos a obrigação de nada deixar impreciso ou no anonimato: são frequentes os artigos em que se citam mais de uma centena de outros, no texto e na bibliografia.

Em resumo, a literacia científica é, por natureza, um processo histórico e uma obra coletiva, fruto da cooperação entre vários contribuintes; é universal, cumulativa e objeto de debate aberto, sempre corrigível. Porque é tudo isto, tem de se precaver, de garantir o máximo possível a sua qualidade, recorrendo ao ceticismo e até a cuidados antissépticos como a condenação absoluta da fraude.

\section{Educar para a literacia científica}

Tomando literacia científica não como conhecimento memorizado de fatos científicos, mas como capacidade de estimar a verossimilhança de afirmações a partir da cientificidade das nossas concepções sobre nós e o mundo, temos de admitir que a "consciência científica" é inexplicavelmente baixa, mesmo em populações com uma escolaridade relativamente elevada. Um estudo realizado com 363 jovens adultos de expressão alemã da Europa central, dos quais 60\% tinham completado o ensino secundário e $29 \%$ tinham diploma universitário, revelou até que ponto estão difundidos na população dos países desenvolvidos certos mitos pseudocientíficos ou se pode fazer aceitar invenções sem qualquer 
suporte como fatos possíveis. (SWAMI et al., 2012). Foram apresentadas afirmações para serem avaliadas numa escala de 1 (tenho a certeza que é falsa) a 7 (tenho a certeza que é verdadeira). As médias observadas para "Só utilizamos $10 \%$ do nosso cérebro", "A mulher engole em média seis libras de batom durante a sua vida" e "Os homens pensam em sexo todos os 7 segundos" foram respectivamente de $3.65,3.59$ e 3.21 . Talvez pior ainda, por ser totalmente inverossímil, observou-se a média de 2.08 para "Chicletes levam sete anos para passar pelo sistema digestivo humano". Entre a crença em mitos e a estimativa de um indicador de atitudes anticientíficas houve uma elevada correlação positiva. Face a resultados como estes, deixa de parecer surpreendente que $1 / 3$ dos brasileiros ainda acreditem que Deus criou o homem há menos de $10 \mathrm{mil}$ anos. (SILVA et al., 2010).

Estas constatações apontam para uma educação muito mais baseada no ensino de fatos do que na compreensão da realidade, que exige análise de conceitos científicos e interpretação de sistemas e modelos. Em Portugal, segundo Afonso (2013), os níveis de exigência conceitual promovidos nomeadamente nos materiais escolares são mais baixos do que os recomendados nos documentos oficiais. O mesmo acontece nas diferentes modalidades de avaliação, pelo professor e nos exames. Como este estudo ainda assinala,

A educação científica no ensino básico conduz à promoção de capacidades cognitivas gerais, capacidades investigativas e conhecimentos científicos simples, de complexidade e abstração baixos, e não promove, com profundidade e frequência, relações entre conhecimentos. Os alunos saem da escolaridade básica com uma visão limitada do que é a ciência e com um desenvolvimento de conhecimentos e capacidades que compromete a sua relação com situações complexas do dia a dia. É natural, por isso, que os alunos venham a ter, na sua vida futura, dificuldades em lidar com situações problemáticas que requeiram raciocínios mais complexos. (AFONSO, 2013, p. 76).

O estudo critica ainda um documento oficial em que se diz que "A utilização de vocabulário específico bem como o uso de termos técnicos e científicos só devem ser introduzidos quando corresponderem a uma necessidade da criança", e que a educação entre o $7^{\circ}$ e o $9^{\circ}$ ano de escolaridade "[...] visa proporcionar aos alunos possibilidades de: Despertar a curiosidade acerca do mundo natural à sua volta e criar um sentimento de admiração, entusiasmo e interesse pela Ciência". Pergunta-se no estudo: "Que dizer perante pretensões de educação científica tão pobres?” (AFONSO, 2013, p. 77). 
No que respeita à preparação para a literacia científica, parece-nos muito importante que a leitura e a escrita de artigos segundo os moldes dos artigos científicos não comecem apenas na Universidade, mas já no ensino secundário. Também é importante que os alunos aprendam a distinguir, naquilo que é acessível pela Internet, entre o que é fiável e o que não é. Num estudo norueguês (ANMARKRUD; BRATEN; STROMSO, 2014), fez-se os alunos (estudantes dos primeiros anos da Universidade) ler um conjunto de documentos. Eles iam pensando em voz alta e no fim escreveram um ensaio. Os que mostraram melhores estratégias de avaliação da informação foram também os que melhor distinguiram a fiabilidade dos documentos e os que demonstraram no ensaio um raciocínio mais argumentativo. São capacidades interligadas e haverá vantagem em agir sobre todas elas.

Não tem o mesmo efeito ler artigos científicos ou artigos de divulgação científica. Num estudo conduzido em Israel, foi manipulada a natureza dos documentos. (BARAM-TSABARI; YARDEN, 2005). Os alunos, do $12^{\circ}$ ano, recebiam textos sobre uma questão de biologia, quer na forma típica de artigo científico, quer de magazine de divulgação científica. Não houve diferença entre os dois grupos no que respeita à qualidade dos resumos que fizeram. Os que leram textos de magazine tiveram atitudes menos negativas em relação à leitura, mas os que leram textos de artigo científico demonstraram uma capacidade de questionamento muito maior nas respostas às duas questões seguintes, sobretudo à primeira $(\mathrm{Q} 1$ : Tem alguma crítica a fazer ao trabalho dos pesquisadores?, teria feito de maneira diferente alguns experimentos? Q2: Pode pensar em algumas outras ilustrações da técnica que foi utilizada pelos pesquisadores para desenvolver o inibidor?). Este estudo mostra que o gênero do texto tem influência na formação científica: a leitura de artigos científicos ajuda a integrar modos de pensar que são os da ciência.

\section{A literacia científica e a literacia literária}

A literacia científica e a literacia literária são manifestações de dois impulsos ou desejos consubstanciais ao ser humano e que, portanto, precedem de muito o aparecimento da literacia: o desejo de conhecer, compreender, e o desejo de contar, narrar. Assim, fomos pesquisadores e narradores antes de sermos letrados, e isso é válido tanto no que respeita à História como ao nosso desenvolvimento na infância. A literacia apenas veio armar-nos de novos instrumentos e suscitar novos caminhos e expressões ao que já existia em nós. Ter essa perspectiva 
permite compreender melhor por que a ciência é um combate permanente aos mitos e à irracionalidade e a literatura de ficção uma mise-en-scène constante de objetivos e sentimentos de sexo/amor, apropriação, domínio, controle, etc.

Os desejos não são independentes uns dos outros. Os nomes que lhes damos resultam de uma análise mental (fruto da necessidade de conhecer, ela mesma associada à vontade de controle e poder e à procura de laços afetivos e sociais, etc.) que isola dimensões distintas da nossa relação com o mundo. Por isso, literacia científica e literacia literária não só partilham raízes profundas, mas estão associadas em muitas das suas expressões atuais. A realidade e a ficção, palavras-chave respectivamente da literacia científica e da literacia literária, não são elas mesmas estranhas uma à outra, porque as une "o possível". A ciência é feita de verificações do possível (ela chama-lhes "verificação de hipóteses") e a ficção é a encenação de possíveis. Quanto ao impossível, ele está presente em ambas: a ciência para conseguir rejeitá-lo e a ficção para criar um quadro de onde melhor se destaque o possível e o real. Mas é o possível, sem qualquer dúvida, nos fazer viver e pensar, à maneira da ciência ou da ficção. Exprimiu-o assim Umberto Eco, em $O$ Nome da Rosa, e não somos os primeiros a citá-lo (tradução livre e resumida, da nossa responsabilidade): Compreendi naquele momento como o meu Mestre raciocinava. Quando não tinha resposta, Guilherme propunha muitas, todas diferentes. - Mas então, ainda está longe da solução? - Estou muito perto, mas não sei de qual. - Então, só tem uma resposta? - Se fosse o caso, ensinaria teologia em Paris! Assim ele se divertia a imaginar o maior número possível de possiveis. (ECO, 1992, p. 330). Não sabemos nós determinar se este é um belo exemplo de ciência na ficção ou de ficção na ciência, e se nesta passagem Eco era mais linguista ou romancista. Cremos que era ambos, sem prejuízo de qualquer e dando a cada uma as vantagens da outra.

Ter muitas respostas só acontece quando se tem questões que se entreabrem para um panorama de possíveis. A questão é isso mesmo, primeiro uma fresta de onde se vislumbra e, após mais aprofundada reflexão, uma abertura de onde se vê, se caminha e se procura. Tanto a literacia científica como a literacia literária são feitas de questões e cada resposta só conta na medida em que conduz a uma nova questão. Era o que nos dizia Paul Bertelson, nosso mestre a ambos, na psicologia experimental. E é o que diziam e dizem os mestres de literatura. "O artista observa, escolhe, adivinha, compõe - estas ações em si mesmas já pressupõem uma questão na origem”, escreveu Chekhov (1888, não paginado) ${ }^{3}$.

Por vezes, as "duas culturas", a da ciência e a da arte, vão além desta comparticipação do eterno retorno da questão. Por vezes comunicam uma com

3 Recomendamos a este respeito a leitura de Monkeys with typewriters, de Scarlett Thomas, romancista e professora de escrita criativa. 
a outra e encontram-se: cientistas em romances, escritores e referências literárias em textos científicos e até conversas imaginadas entre uns e outros. Escrevem-se romances "científicos" e apresenta-se a ciência como um romance. De alguns, ainda poucos, nem se pode dizer se são mais cientista (ou filósofo, ensaísta,...) que romancista (ou contista, autor de teatro,...) ou o contrário.

Parece haver maior temor da parte dos cientistas que a ficção deforme a "verdade" científica que da parte dos ficcionistas que a ciência desnature a "realidade" das vidas e dos sentimentos e a sua expressão literária. Esse temor justifica-se: as más ficções são eliminadas, se não imediatamente, com o tempo; ao passo que os "mitos científicos" (passe o paradoxo) sobrevivem e contaminam. De fato, como explica Chassay (2006), parece hoje certo que a maçã de Newton nunca lhe caiu na cabeça, que ele se serviu dessa imagem para explicar a teoria da gravidade a uma sobrinha, de quem se dizia que era a única mulher que não desprezava (por que uma maçã?, terá ele criado um mito ao sucumbir a outro mito?). Muito mais grave é o mito de que Darwin teria afirmado que o ser humano descende do macaco, como resultado de uma evolução linear no sentido de uma perfeição cada vez maior; na realidade, a sua teoria era que as espécies descendem de outras por modificação devida à seleção natural, e nunca estabeleceu uma relação de descendência direta entre o ser humano e o macaco. Foi a seleção natural que fez com que hoje só exista uma espécie de Homo (o "sapiens"), tendo as outras sido eliminadas. A ciência tem, portanto, mais a perder, na sua versão pública, com a sua permeabilidade à ficção vulgar, do que a ficção literária de qualidade com a assimilação da ciência e dos cientistas.

A literacia científica e a ficção literária confrontam-se com a mesma enorme dificuldade, a que resulta da necessidade de dar nomes aos conceitos abstratos com que uma e outra explicam as respetivas realidades. O léxico transforma-se e enriquece-se sob a influência tanto da ciência (e das modificações que as tecnologias, sobretudo por via da ciência, e as atividades humanas provocam na realidade) como da literacia em geral incluindo a literária. Face a esse mundo único mas polivalente, físico, biológico, social e mental, a ciência e a ficção narrativa, se interagirem mais profundamente, podem cooperar na determinação do conteúdo e da extensão dos conceitos e das velhas, novas e futuras palavras que os denotam.

Este nosso otimismo decorre da nossa própria posição de pesquisadores que, quando possível, se entregam também à ficção (JM: um romance em Portugal; RK: um romance em francês num cenário brasileiro) ou à apresentação ficcional de temas científicos ${ }^{4}$.

4 MORAIS, J.; KOLINSKY, R. A última metamorfose de Zeus. Porto Alegre: Movimento, 2015. 


\section{A literacia científica no contexto da sociedade capitalista e, particularmente, do capitalismo neoliberal}

Todas as literacias, científica, literária, educacional, da saúde, ecológica, etc., se confrontam a partir de ângulos de visão diferentes com o mundo real, o da sociedade capitalista, da globalização neoliberal e dos governos pretensamente democráticos e poderes com eles conluiados.

Não sendo a literacia científica mais do que uma forma da literacia enquanto capacidade de leitura e de escrita, e dependendo desta, há fatos que não podem ser ignorados. Segundo as Nações Unidas e a Organização das Nações Unidas para a Educação, a Ciência e a Cultura (UNESCO), é-se iletrado (no nosso caso, analfabeto) quando se é incapaz de ler e escrever uma frase simples relacionada com a vida quotidiana. No Brasil há cerca de $10 \%$ de analfabetos entre os indivíduos com pelo menos 15 anos de idade. Quem não é analfabeto é, por exclusão, alfabetizado. Porém, a realidade é diferente quando se tem em conta que entre ler e escrever uma frase simples e poder compreender e produzir textos como os que hoje em dia são necessários para se participar de maneira livre e eficiente na vida profissional, social e política de um país, há uma grande distância. Essa distância foi caracterizada nos inquéritos do Programa Internacional de Avaliação de Alunos (PISA) sobre a leitura segundo uma série de níveis (seis, sendo o nível 1, o mais baixo, subdividido em 1a e 1b). No conjunto dos países da OCDE, 29.5\% dos adolescentes de 15 anos (escolarizados) estão acima do nível 3; 29.1\% encontram-se no nível 3; e 41.4\% estão abaixo dele. A exigência para que o leitor atinja pelo menos o nível 4 é que ele seja capaz de

[...] localizar e organizar vários pedaços de informação contida no texto, [...] interpretar o significado de nuances de linguagem numa secção do texto tendo em conta o texto global [...] compreender e aplicar categorias num contexto não familiar, (e utilizando) conhecimento formal ou público fazer hipóteses sobre um texto ou avaliá-lo criticamente. (OECD, 2013, p. 193).

Os níveis inferiores não requerem leitura crítica. Assim, para ser leitor no nível 3 é suficiente integrar várias partes de um texto de maneira a identificar a ideia principal, compreender uma relação ou construir o significado de uma palavra ou frase. Acontece que, segundo os nossos próprios cálculos a partir do relatório PISA relativo a 2012, no Brasil, só 5\% dos adolescentes estão acima 
do nível 3. Eles formarão, portanto, na idade adulta, uma "oligoliteracia", e o Brasil continuará a ser, por muitos anos, uma oligarquia (governo de uma elite), a menos que ocorra uma revolução educacional. No nível 3 só há $16 \%$, e abaixo do nível 3 os restantes 79\%. Assim, apenas 1 em 5 adolescentes escolarizados (aos 15 anos) serão letrados, os restantes 4 serão maus leitores ou analfabetos funcionais.

Esta situação, que reserva a literacia a uma minoria de brasileiros, não tem impedido o desenvolvimento da literacia científica. Os poderes públicos podem apoiá-la no limitado âmbito da população universitária favorecida, porém com três consequências: (1) desprezam as potencialidades cognitivas da grande massa restante; (2) mantêm quatro quintos da população brasileira num estado de conhecimento em todos os domínios praticamente nulo, o que afeta grandemente as suas condições de vida; e (3) reproduzem e agravam uma dramática desigualdade que, para além de ser imoral, impede caminhar para a democracia. Acrescenta-se a isto o fato de a literacia científica ser produzida, sobretudo, nas universidades públicas, com acesso restrito a quem está bem preparado e em regime de gratuidade de inscrição, enquanto aqueles que, a seu próprio custo e/ou das famílias, conseguem pagar estudos em universidades privadas são, na maior parte destas, formados de maneira profissionalizante para a mera aplicação de conhecimentos acumulados sem real exame crítico.

Ao nível mundial, muitos milhões de pessoas fazem ciência ou participam em algum estádio do processo. O número de jovens com capacidades e desejosos de ingressarem num programa doutoral aumentou muito nas últimas décadas, mas as políticas de austeridade em muitos países fazem com que apenas uma pequena percentagem, provavelmente à volta de $20 \%$, consiga ser aceita. Em seguida, a seleção para pós-doutoramento é impiedosa, e mais ainda a passagem a uma posição acadêmica de duração indeterminada. Este sistema é altamente pernicioso para o processo de produção científica: a exigência de numerosas publicações em um tempo muito curto faz com que os jovens pesquisadores não tenham tempo suficiente para amadurecer o seu projeto, aprofundar o seu conhecimento do domínio e mesmo do tópico escolhido, assim como dos instrumentos de que precisam, e conhecer outros domínios e instrumentos suscetíveis de serem explorados para o seu próprio projeto, já que disso depende em grande parte a criatividade. Outra consequência deste modo de fazer ciência é ela tornar-se cada vez mais factual, perdendo muito em elaboração teórica.

Como a ciência é gerida pelos poderes públicos, que servem aos interesses do capitalismo neoliberal, e como ela alimenta a tecnologia e é alimentada por esta, ela brota cada vez menos dela mesma e dos jovens que se juntam a ela, e é decidida cada vez mais em comissões que recebem decisões vindas dos governantes sobre os eixos programáticos que devem ser privilegiados. Por 
via destes eixos, a ciência, que precisa de liberdade para ser criativa e progredir, e que se julgava livre, está entrando de fato nos eixos, isto é, nos eixos do sistema capitalista e dos seus interesses econômicos e financeiros. A luta pela autonomia da ciência e das suas instituições é um imperativo urgente que deve unir os cientistas, os jovens pesquisadores e a população em geral. Para mobilizar esta, e porque a maioria da população é pouco ou subletrada, é crucial que a comunidade científica saiba dirigir-se a ela, explicando o que é e deve ser a ciência, por que é necessária, como e em quê ela pode mudar para melhor a vida das pessoas, e quais são os perigos que a ameaçam.

O capitalismo neoliberal, pela própria natureza dos seus mecanismos, alimenta uma cultura de competição, em vez de emulação e cooperação. A pressão que essa cultura exerce sobre cientistas e pesquisadores, na Universidade e mesmo na escola, tem conduzido a um aumento considerável da desonestidade, da sonegação de informação e da transmissão de informação falsa entre colegas e da fraude. A fraude escolar, acadêmica e científica, é favorecida pela desigualdade econômica. Observou-se, por exemplo, que a fraude acadêmica, baseada na utilização ilegítima do Google, é maior nos Estados norte-americanos em que a desigualdade é maior do que naqueles em que esta é menor. Isso explica-se pelo fato de a desigualdade contribuir para aumentar a desconfiança entre os indivíduos. (NEVILLE, 2012). Em outro estudo, estudantes de uma escola internacional de gestão na Suíça foram convidados a ler um extrato de uma suposta conferência de um prêmio Nobel que estabelecia um paralelo entre a vida e a economia. Numa versão, elogiava-se os valores de sucesso, riqueza, reconhecimento social para chegar à ideia de que uma boa economia se baseia na ambição pessoal e na autorrealização. Na outra versão, elogiava-se os valores de justiça social, gestão responsável, sabedoria, para chegar à ideia de que uma boa economia se baseia na igualdade e na paz. Verificou-se, num questionário ulterior sobre o que pensavam das fraudes, que os estudantes que ouviram a apologia do autoengrandecimento mostraram uma maior aceitação da fraude do que os que ouviram a apologia da orientação social. (PULFREY; BUTERA, 2013). A exageração cultural do objetivo de sucesso juntamente com a atual dificuldade de acesso às profissões que propiciam um alto estatuto podem conduzir a uma banalização de comportamentos que hoje ainda são considerados imorais.

Neste quadro, a literacia científica tem certamente uma função social e ética importante. Os pesquisadores e cientistas não podem fechar-se nos seus escritórios e laboratórios. A paixão da ciência é grande e desejável, brota de um de nossos impulsos primários, mas precisamente por isso ela deve socializar-se, defender a liberdade de escolha e de pensamento que faz a sua criatividade e realizar-se no respeito pela verdade e pela equidade. 
Há quem argumente, defendendo o capitalismo, que tem sido sob este sistema socioeconômico que a ciência se tem desenvolvido tanto. Afinal, dizem, é o capitalismo que faz a ciência. Isto seria como dizer que o capitalismo é que fez aumentar a população mundial de um bilhão para quase oito bilhões, esquecendo que cada novo ser humano é feito por um pai e uma mãe, ou de maneira mais "científica", pela fecundação de um óvulo por um espermatozoide. Certamente, o capitalismo tem um papel no aumento da população e no desenvolvimento da ciência e em tudo o que nos acontece já que vivemos em sociedade capitalista. O capitalismo é um sistema de criação e acumulação de capital através da diferença, positiva, entre o valor do bem produzido pelo trabalho humano (e depois vendido para utilização e/ou consumo) e o custo deste (o salário). A concorrência entre capitalistas incentiva-os a aumentar a eficiência dos meios de produção (pela tecnologia, e esta depende da ciência) e a adequação do trabalho a estes meios (pela formação profissional, portanto, pela educação à qual a ciência contribui). O capitalismo, para prosperar, precisa da ciência e de mais força de trabalho. Portanto, não é o capitalismo que faz mais ciência e mais seres humanos, são a ciência e as crianças futuras trabalhadoras que, sem para isso terem sido consultadas, fazem mais capitalismo. Como se diz em ciência e não só, a questão formulada acima é uma má questão. As boas questões são: está o capitalismo neoliberal orientando a ciência em função de seus interesses e desviando-a, pelo menos parcialmente, do interesse do conhecimento e do bem-estar geral?, e está o capitalismo neoliberal desprezando a falta de literacia da maior parte da população mundial e orientando a literacia da menor parte para servir melhor os seus interesses próprios (produção, venda, enriquecimento) em vez de servir todos em compreensão de si e do mundo, qualidade de interação social, participação criadora na cultura da humanidade e vida feliz num meio, o nosso planeta, que - se o capitalismo depredador continuar - por o fazermos sofrer nos fará também sofrer? As respostas que damos a estas questões estão nas páginas acima.

\section{A importância da psicologia científica, para o Brasil e para a escola em geral}

Esta dupla nota final impõe-se.

Por razões que só muito remotamente têm a ver com o capitalismo mas, mais diretamente, com a História da cultura intelectual no Brasil, a utilização da metodologia experimental em psicologia, em particular para estudar as 
capacidades cognitivas e linguísticas, tem sido muito limitada. No Brasil, a psicolinguística "pertence" à linguística, que, satisfeita, não abre mão dela. A psicologia, de modo geral, é considerada como um discurso, das "humanidades", esquecendo completamente ou quase as ciências matemáticas, físicas, biológicas e bioquímicas. No mínimo dos mínimos, os estudos universitários de psicologia deveriam incluir, desde o primeiro ano, cursos de qualidade em psicologia cognitiva experimental, em matemática e estatística, e cursos de psicolinguística cognitiva (experimental, obviamente). A ciência (insistimos: experimental) da literacia deveria ser ensinada em psicologia, mas também nos estudos de educação e de formação de professores. Tendo em conta os dados apresentados acima sobre a situação dramática da literacia no Brasil, a necessidade desta mudança é evidente e terá de vencer o conservadorismo, isto é, hábitos e interesses estabelecidos e a falta de professores formados para tal.

A presente contribuição tem como principal objeto a literacia científica. Este é o momento de insistir no fato de que a ciência também se ocupa da literacia. Hoje, no mundo, há uma ciência da literacia que pode inspirar princípios pedagógicos apropriados a uma boa alfabetização, e muitos estudos têm mostrado que a aplicação desses princípios é particularmente útil para as crianças desfavorecidas. Enquanto a literacia científica sobre a literacia não tiver chegado como deve ao meio escolar (felizmente há casos, por iniciativa individual ou de Organizações Não Governamentais (ONGs), em que isso acontece, produzindo resultados excelentes), muitas crianças continuarão a sair da escola minimamente alfabetizadas, sem condições para se tornarem letradas.

Mesmo em países em que a ciência da literacia está muito desenvolvida ela pena em chegar à formação de professores e, por via deles, ao meio escolar. Para fechar esta contribuição, sugerimos que se reflita sobre os resultados do seguinte estudo, realizado nos Estados Unidos. Foram testados no $4^{\circ}$ e no $8^{\circ}$ anos 1.367 alunos de 32 escolas. A variável escola explicou entre 24 e $34 \%$ das diferenças individuais nos desempenhos obtidos numa bateria de testes de inglês e matemática. Porém, a escola não explicou as diferenças individuais nas habilidades cognitivas: apenas $2 \%$ em memória de trabalho e em raciocínio. Mesmo quando houve melhoria entre o $4^{\circ}$ e o $8^{\circ}$ ano nos testes de inglês e matemática, não houve melhoria correlativa nas habilidades cognitivas. (FINN et al., 2014). O mesmo aconteceu num estudo sueco sobre 100 mil crianças, citado por estes autores. O que aumenta as habilidades cognitivas, a chamada inteligência fluida, são treinos específicos, por exemplo, sobre a memória de trabalho, mas as escolas em geral estão totalmente orientadas para a aquisição de conhecimentos, para a chamada inteligência cristalizada. Isto é, com as escolas atuais, as nossas crianças arriscam-se a ficar cristalizadas. 
Concluindo: a literacia científica, que inclui a ciência da literacia, é uma forma específica de leitura e de produção de texto que - esperamos tê-lo mostrado - deve ser entendida na sua relação com a ciência (cada uma depende da outra) e com outra forma de literacia, aparentemente nos seus antípodas, mas que na realidade podem se fertilizar mutuamente.

\section{REFERÊNCIAS}

AFONSO, M. Que ciência se aprende na escola? Lisboa: FFMS, 2013.

ANMARKRUD, O.; BRATEN, I.; STROMSO, H. I. Multiple-documents literacy: Strategic processing, source awareness, and argumentation when reading multiple conflicting documents. Learning and Individual Differences, v. 30, p. 64-76, 2014.

BARAM-TSABARI, A.; YARDEN, A. Text genre as a factor in the formation of scientific literacy. Journal of Research in Teaching Science, v. 42, p. 403-428, 2005.

CHASSAY, J.-F. Texte et image: Les signes piégés de la science, de la vulgarisation à la science. Image et Narrative, On-line Magazine, 2006. Disponível em: <https://www. imageandnarrative.be/inarchive/iconoclasm/chassay.htm>. Acesso em: 15 nov. 2016.

CHEKHOV, A. Letter to A. S. Suvorin. 30 maio 1888.

COLLINS, A. National Science education standards: A political document. Journal of Reserach in Science Teaching, v. 35, p. 711-727, 1998.

DE BOER, G. Scientific literacy: Another look at its historical and contemporary meanings and its relationship to science education reform. Journal of Research in Science Teaching, v. 35, p. 582-601, 2000.

ECO, U. Le Nom de la Rose. Paris: Livre de Poche, 1992.

FINN, A. S.; KRAFT, M. A.; WEST, M. R.; LEONARD, J. A.; BISH, C. E.; MARTIN, R. E.; SHERIDAN, M. A.; GABRIELI, C. F.; GABRIELI, J. D. Cognitive skills, student achievement tests, and schools. Psychological Science, v. 25, p. 736-744, 2014.

KROMHOUT, R.; GOOD, R. Beware of societal issues as organizers for Science education. School Science and Mathematics, v. 83, p. 647-650, 1983.

MORAIS, J. Lire, écrire et être libre. De l'alphabétisation à la démocratie. Paris: Odile Jacob, 2016.

NEVILLE. Do economic equality and generalized trust inhibit academic dishonesty? Evidence from state-level-engine queries. Psychological Science, v. 22, p. 235-242, 2012. 
NORRIS, S.; PHILLIPS, L. M. How literacy in its fundamental sense is central to scientific literacy. Science Education, v. 87, p. 224-240, 2003.

NORRIS, S. P.; PHILLIPS, L. M.; SMITH, M. L.; GUILBERT, S. M.; STANGE, D. M.; BAKER, J. J.; WEBER, A. C. Learning to read scientific text: Do elementary school commercial reading programs help. Science Education, v. 92, p. 765-798, 2008.

NSTA. National Science Teachers Association. NSTA position statement on schools science education for the 70's. The Science Teacher, v. 38, p. 46-51, 1971.

OECD. Organização para a Cooperação e Desenvolvimento Econômico. 2012 's PISA Report, 2013.

PULFREY, C.; BUTERA, F. Why neoliberal values of self-enhancement lead to cheating in higher education: A motivational account. Psychological Science, v. 24, p. 2153-2162, 2013.

SHAMOS, M. The myth of scientific literacy. New Brunswick, New Jersey: Rutgers University Press, 1995.

SILVA, H. M.; PRADO, I. G. O. Creationism and inteligente design: Presence in the Brazilian educational policy. Procedia Social and Behavioral Sciences, v. 2, p. 5260 5264, 2010 .

SWAMI, V.; STIEGER, S.; PIETSCHNIG, J.; NADER, I. W.; VORACEK, M. Using more than $10 \%$ o four brains: Examining belief in Science-related myths from an individual diferences perspective. Learning and Individual Differences, v. 22, p. 404-408, 2012.

TENOPIR, C.; KING, D. W. Communication patterns of engineers. Hoboken: New Jersey, 2004.

WEBB, P. Science education and literacy: Imperatives for the developed and developing worls. Science, v. 328, p. 448-450, 2010.

Texto recebido em 09 de agosto de 2016. Texto aprovado em 09 de agosto de 2016. 